\title{
Coronavirus Disease (Covid-19): Reviews, Applications, and Current Status
}

\author{
Tanweer Alam ${ }^{1}$ \\ ${ }^{1}$ Islamic University of al-Madinah al-Munawarah
}

July 25, 2020

\begin{abstract}
Currently, the COVID-19 has directly affected the millions of humans lives. The symptoms of the disease involving fever, malaise, chest infection, and breathing difficulties, were identified, and its existence is continuously becoming restructured. The World Health Organization (WHO) had mentioned the wide diagnostics test besides COVID-19 that would also assist medical facilities to recognize infectious diseases as well as currently focusing efficiently on preventing and afterward defeating this viral disease. The infection is usually transmitted among human beings in direct contact, greatest through the liquid bubbles generated through cough, sneeze, or speaking. This paper reviews the COVID 19 pandemic, its history, current updates, contact tracing applications, and use of emerging technologies like the Internet of Things (IoT) and Blockchain for stopping the spreading and provide service online to the patient from a distance.
\end{abstract}

\section{Hosted file}

Coronavirus Disease (Covid-19)- Reviews, Applications, and Current Status.pdf available at https://authorea. com/users/329478/articles/472222-coronavirus-disease-covid-19-reviewsapplications-and-current-status 